\title{
Spiritual and Moral Aspects of the Formation of a sustainable Society
}

\author{
Avazov Komil Hollievich \\ Co-researcher of the Uzbek National University named after M. Ulugbek, Tashkent, Republic of Uzbekistan \\ *Corresponding Author: Avazov Komil Hollievich, Co-researcher of the Uzbek National University \\ named after M. Ulugbek, Tashkent, Republic of Uzbekistan
}

\begin{abstract}
Spirituality protects both the freedom of the individual, and freedom, the independence of the nation. The study of social evolution, the logic of social processes creates the opportunity to identify changes in the system of historical, spiritual, cultural and moral values - accordingly - the dynamics of the development of the society in situations of risks, challenges and threats. To date, mankind has accumulated so many weapons and ammunition that it is enough to destroy the globe several times. However, the greatest danger today is the ongoing ideological struggle for the souls and consciousness of people, especially the younger generation. Today, the decisive role is played not by battles at nuclear test sites, but by fighting on the ideological front. Never forget this bitter truth. The formation of ideological immunity is determined by the degree of its conformity with the nature of the people, the way of life and thinking, and most importantly how it reflects the national interests and aspirations of society. Only such an ideology will stand the test of time and life, people will believe it and accept it as a belief.

Keywords: Threatening society, spiritual development, spiritual basis, globalization, ideological threat, degradation, stable development, export of democracy.
\end{abstract}

In modern conditions, the spiritual development of society is becoming one of the most important factors in ensuring its national security. Contradictory influence of globalization on modern life reveals, along with its positive trends, and negative, associated with its influence on the growth of spiritual threats.

In this regard, only familiarizing with the invaluable cultural heritage, modern achievements, the formation of free, independent thinking will help to develop among the population especially among the younger generation immunity in relation to spiritual threats.

Therefore, the qualitative features of the spiritual world of the individual, social strata and groups determine the state of social relations in the aspect of their stability and stability, the dynamics of development and reproduction. Socio-philosophical analysis of the spiritual sphere as a factor of national security focuses on the consideration of universal meanings, essential features and characteristics, depth - the actualized phenomena of social life.

The disruption of the balance of power in the previously bipolar world gave rise to the desire of individual leaders and states of the West to impose their understanding of democracy on the rest of the world's peoples, in essence, their own model of state organization.

Such attempts, naturally, were rejected and evaluated as a factor of undermining confidence between peoples after the end of the Cold War. Therefore, the issues of spirituality and enlightenment, the upbringing of the younger generation in the spirit of healthy patriotism, progressive national and universal values acquire particular urgency.

In Uzbekistan, much attention is paid to issues of spirituality, since national reconstruction and national progress depend on their right decision. Real spirituality in the republic is recognized as a priority along with the economy.

The first President of the Republic of Uzbekistan, IA Karimov, highlighted the problem of further spiritual renewal of the society among the most important priorities of development of Uzbekistan for the near future. We all, as he emphasizes, "must clearly realize that the state of affairs in other spheres depends on the spiritual revival of the people, the preservation of traditions, the development of culture and art, and how effective the reforms are. 
He also noted that: "Strengthening and developing the spirituality of the people is the most important concern of the state and society in Uzbekistan. Further - the energy of man, people, society, state "[Karimov 1996: 77-78].

Consequently, spirituality protects both the freedom of the individual, and freedom, the independence of the nation. The study of social evolution, the logic of social processes creates the opportunity to identify changes in the system of historical, spiritual, cultural and moral values - accordingly - the dynamics of the development of society in situations of risks, challenges and threats.

The conceptual status of the discipline of social philosophy and political science allows structurally to present national security in the solidity of its numerous substructures and elements. In order to counter the threats to national security, the forces of providing it (primarily state security and public security) in cooperation with the institutions of civil society ensure the preservation of the socio-historical, cultural and spiritual heritage.On this basis, national priorities for the development of the spiritual sphere are to preserve and strengthen the moral foundations of society, historical traditions, the cultural and scientific potential of the country.

Consequently, the spiritual foundations of society are, first of all, an active attitude toward reality, striving for a specific goal, ideals, organizing their activities in accordance with them. Only when the harmonization of connections between the components in the system "man - society - nature, norms and guidelines for the construction of a humanistic society with a highly developed political, legal, moral, ecological, artistic culture will be laid in the foundation of the spiritual foundations of independence. Spiritual foundations are based on four pillars:

- Commitment to universal values;

- strengthening and development of the spiritual heritage of our people;

- free self-realization by a person of his potential;

"Patriotism" [Karimov1996: 77-78]. And adherence to universal values is the social orientation of our new emerging civil society.

Preservation of the system of basic values opens up opportunities for the progressive development of the individual, society and the state. In this case, spiritual security presupposes the provision of conditions for stable development and allows the state to solve the urgent tasks of economic, social and political development. Simultaneously, the analysis of the state of the spiritual and cultural and moral spheres helps to identify those negative trends in various areas of life that can lead to the emergence of threats to national security.

Without the support of spiritual guidelines, without the development of human qualities, the stable development of society is inconceivable. In general, the new system of spiritual values should be designed so that a person feels himself part of the socio-natural environment, as was the case with the domination of the mythological worldview.

The criterion, in this case, is the increase in the role of universal human values in the history of mankind, the increase in their share in the life of society. We are talking about such vital values as the environment, the human race and human life, the individual and her social status, the safety and effectiveness of technology, reasonable satisfaction of needs.

Preservation of the system of basic values opens up opportunities for the progressive development of the individual, society and the state. In this case, spiritual security presupposes the provision of conditions for sustainable development and allows the state to solve the urgent tasks of economic, social and political development. Simultaneously, the analysis of the state of the spiritual and cultural and moral spheres helps to identify those negative trends in various areas of life that can lead to the emergence of threats to national security. Without the support of spiritual guidelines, without the development of human qualities, the stable development of society is inconceivable. In general, the new system of spiritual values should be designed so that a person feels himself the part of the socionatural environment, as was the case with the domination of the mythological worldview.

The criterion, in this case, is the increase in the role of universal human values in the history of mankind, the increase in their share in the life of society. We are talking about such vital values as the environment, the human race and human life, the individual and her social status, the safety and effectiveness of technology, and reasonable satisfaction of needs. 
The social vanguard of the spiritual sphere of social life in science, art, literature, etc. determines the direction of society's activity, the strategy and tactics of educating the perfect personality of its time, ensures the sustainable development of society, the harmony of its social institutions. The social experience of the spiritual life of the societies of the East and Central Asia shows that quarrels and confusions, born in the minds of people, appear as one of the most significant causes of the degradation of society, as one of the most important functions that reveal the negativism of subjective factors, a departure from the line of sustainable development of society.

Let us turn again to the speeches of the head of state, for they formulate the problems and tasks of practical politics. "If economic growth, progress is the body of our society, then spirituality, enlightenment, maturity of political consciousness is its spirit, mind, soul. To build a great state, to achieve a great future, it is necessary to educate intelligent, enlightened people, proud of their past, great values, a nation of people who believe in the future "[Karimov 1996: 163-164].

On this basis, national priorities for the development of the spiritual sphere are to preserve and strengthen the moral foundations of society, historical traditions, the cultural and scientific potential of the country. Preservation of the system of basic values opens up opportunities for the progressive development of the individual, society and the state. In this case, spiritual security presupposes the provision of conditions for stable development and allows the state to solve the urgent tasks of economic, social and political development.

Spirituality, above all, protects the nation, national culture, way of life. It fulfills the function of a social and cultural filter and tries to prevent the penetration of alien phenomena into the national life, undermining the national, not conforming to the moral, aesthetic, philosophical convictions of the nation. At the same time, Uzbekistan has faced many new contemporary problems, many of which present a real threat to the sovereign existence of the state.

Today it is necessary to recognize that the emerging spiritual crisis is becoming a threatening factor for the existence of man and mankind. Its manifestation is directly related to a sharp exacerbation. Therefore, the stability and viability of the state is determined, first of all, by the moral and spiritual levels of its population, and not by the state of the economy. Consciousness largely determines being. History gives many examples, beginning with the demise of the Roman Empire, when in general economically prosperous states perished as a result of a fall in the moral standards of the population, in particular, the growth of corruption among state officials.

Without providing national-spiritual security at the proper level, it is impossible to achieve national security. The level of security of the national security system remains interconnected. In reality, we are witnessing this process. In the global world there is a process of hegemony over mankind, instead of using weapons, the priority is to capture the mind, soul and mind of man. The inevitability of a complex struggle in the sphere of spirituality is shown. Full awareness of the processes taking place in the spiritual sphere, the implementation of state policy in this area, thorough knowledge of the mechanisms of fighting against destructive ideas by the leaders of state power is a demand of the time. In the end, the Republic, it was noted that the upbringing of spirituality, its improvement, in addition, all the tasks in this area, are the main and priority tasks of state significance. Therefore, the state policy related to the development of spirituality and cultural and educational work should be constantly at the center of our attention.

The strengthening, renewal and "repair" of one's own history must be continuously and responsibly conducted by each people, just as the "defense" of one's history should be part of the work of the whole system of national security "[Kara-Murza 2008: 214].

Consequently, without the support of spiritual guidelines, without the development of human qualities, the formation of a threatening society is inconceivable.

In general, the new system of spiritual values should be designed in such a way that a person feels himself part of the socio-natural environment, as was the case with the domination of the mythological worldview.

The criterion in this case is an increase in the role of universal human values in the history of mankind, an increase in their share in the life of society. We are talking about such vital values as the environment, the human race and human life, the personality and its social status, the safety and effectiveness of technology, the reasonable satisfaction of needs. 
The socio-philosophical concept of the spiritual security of Uzbek society in the conditions of modern geopolitical rivalry, in which the system of scientific concepts and principles of providing this type of security is grounded.

Spiritual security can not be understood as exclusively religious or cultural security. Spiritual security is a unique and universally universal phenomenon characterized by systemic unity, integrity of cultural, religious, scientific, educational, information and ideological security. Ensuring spiritual security is not the prerogative of only state institutions and bodies.

The subjects of ensuring spiritual security are also patriotic oriented citizens and institutions of civil society, in particular, the mass media, which are one of the components of the non-state part of the system for ensuring spiritual security.

Spiritual security is considered as one of the types of national security and represents a state of protection of the spiritual sphere of modern Uzbek society. It includes cultural, ideological, information-psychological, scientific, educational and religious security as its subspecies and is characterized by respect for the interests of the individual, society and the state, protected from internal and external threats of traditional spiritual (intellectual, moral, aesthetic) values, mainly, Individual, group and mass consciousness.

The components of the object of ensuring spiritual security are: national self-awareness, generally accepted traditions of the organization of public life, moral and psychological unity of the nation, expressed in active support of the domestic and foreign policies of its state.

In this regard, we can highlight the most important problem of ensuring the spiritual security of Uzbek society and the main threat to the foundations of spiritual life in modern Uzbekistan - the cultivation of spiritual values alien to the mentality of the Uzbek people, the introduction of destructive life priorities, the ideologist, the goals and tasks facing the individual and the society as a whole .

The effectiveness of ensuring the spiritual security of society depends not only on the implementation of measures to protect spirituality within the spiritual space of Uzbekistan, but also from the realization of the nation's constant spiritual expansion in modern geopolitical conditions around the world. Uzbekistan can preserve its sovereignty and statehood only if the majority of the society and (or) its passionary part adopt unified national spiritual values. The spiritual space of Uzbekistan is not limited to the state-territorial limits.

Strengthening, stable and sustainable development of the state is connected not only with organizational and creative affairs, but also with changes in spiritual life. The spiritual foundation of independence was the aspiration of the peoples of Uzbekistan to freedom, social justice and the growth of national self-awareness. Noting this feature of society, it is important to emphasize that the reassessment of spiritual, moral and other values acquires its own specific character. This specificity is determined by the peculiarities of the functioning of the spiritual sphere of society's life [Abdurakhimov 2008: 149].

Spirituality reflects the national identity, mentality, historical memory of the people. If people lose their historical memory, their mentality, they lose their national identity, and ultimately independence.

Spirituality, protects both the freedom of the individual, and freedom, the independence of the nation. The threat to spirituality is a threat, as it seeks to tear man away from genuine national and universal values, to channel him into the channel of dubious, imaginary values of "mass culture", political and religious radicalism [Otamuratov 2015: 4].

In this process, important are the properties in social relations, which distinguish value from other phenomena. Here an important role is played by the presence of an appraisal component of human activity, which gives it a kind of personal coloring and significantly hampers the object relation to the world.

It is well-known phenomenon of the Uzbek national spirit, which is based on the great idea of a strong connection of people, allowing Uzbeks for centuries to be strong, healthy and decent nation. The concept of spirituality, defined as the manifestation of aspiration to the perfect, holistic, ideal, in the true sense of the word, came into the world together with Islam. 
Religion has always made a great contribution to the development of spirituality, enlightenment, into the world civilization. And today, speaking of statehood, our prospects, we must treat religions with respect both as a national and as a universal value "[Karimov 1995: 58].

It is appropriate to recall here, and that according to the Constitution of the Republic of Uzbekistan, in a free multiethnic country separate from the state are more than ten confessions, preaching, along with the religion of Islam, Orthodoxy, Judaism and other beliefs. Therefore, the current stability in our country, its prospects and progress are determined by different groups of society. If we want to build a just, free, stable, threatening society, we must remember that the ways of accomplishing this noble goal coincide with the millennial religious beliefs.

The moral law, so important for the modern Uzbekistan, accompanied in the Uzbek traditions categories "conscience" which carries such meanings as the intelligence, understanding, knowledge, inner belief in something that is given to man outside the law. Spiritual and moral context of social processes and human existence in a particular society has always caused a certain resonance, both among religious - social and philosophical thought, as well as in the works of the classics of Uzbek literature.

Withdrawal spiritual - moral component civilized "cores", which, in essence, its center, is fraught with general national depersonalization, loss of orientation between right and wrong.

Speaking about the high significance of the great traditions of Russian classics, as reflected in the works of Alisher Navoi, Babur Zahriddina philosophical writings AN Farabi, Abu Rayhan Biruni, AlKhwarizmi and thoughts of great Islamic scholars at-Termizi, Imam Bukhari emphasizes that only Its preservation can also prevent a spiritual crisis. Therefore, outside the cultural (spiritual) connection, the socium is threatened by the transformation into chaos and into the arena of the struggle of all against all. " You can not revive society without reliance on the people, without spiritual recovery of the common people.

Today the development of the events of the interstate struggle on the borders of spirituality raises the importance of the policy pursued by the head of our state. In fact, the view of spirituality as a statesignificant sphere is the result not only of looking to the future, but also an in-depth study of the spiritual past, and if necessary, of the historical heritage.

Simultaneously, the analysis of the state of the spiritual and cultural and moral spheres helps to identify those negative trends in various areas of life that can lead to the emergence of threats to the national security of Uzbekistan. This emphasizes the importance of socio - philosophical analysis, allowing to explore specific forms of self - determination and self - realization of citizens, the patterns and mechanisms of their consciously volitional and spiritual and moral activities.

Of particular interest is the individual - personal experience in defining the boundaries of selfexpression in accordance with the directions of social development, introducing innovative changes into it, enriching the vital world, forming public mutual support and solidarity, humanistic tendencies in the life of society.

Speaking about the content side of the formation of a threatening society, it would be wrong to reduce these issues only to social, political, economic, environmental problems. Although it is clear that without their decision to form a threatening society and stable development of it in principle is unrealizable. Therefore, spirituality and economics do not oppose each other, but supplement and strengthen each other, develop in interaction with each other. This is the way to national perfection.

Spirituality, by its very nature, resists chaos: it is aimed at transforming it into an orderly system through norms, rules, values and assessments, organizing the implementation of actions, communications, socio-cultural institutions, structures, etc.

However, the problem of spirituality is of particular importance, since one of the causes of the modern civilization crisis is the spiritual impoverishment of mankind, the catastrophic lag of spirituality from the economic and technical progress of civilization. It is here that the causes of both growing ecological catastrophes and social conflicts are hidden.

The way out of this situation is seen in one: in mobilizing the spiritual potential of mankind in search of ways to stabilize the current situation, overcoming the spiritual crisis. 
In the opinion of N.L. Muskhalishvili, V.M. Sergeev and others, it is spirituality, as a catalyst of society, that will create conditions for more effective implementation of radical social and economic reforms, will allow to improve political regimes and institutions, create new systems of motivation and stimulation of labor.

Evidently manifested in recent decades, first of all, the solution of current problems is impossible without changing traditional norms and moral principles to create a sustainable society, without increasing the social responsibility of each person for the consequences of their activities. "External restrictions, legal prohibitions are in themselves powerless if their need is not supported by a clear moral feeling, an inner conviction that certain actions can not be justified by no apparent benefit, no attraction" [Muskhalishvili 1996: 13].

The stability of the development of the spiritual sphere of social life, reflected in its scientific theory and scientific history, proves that the essence of its reflection in theory is the cognition of the laws of the development of society, and the essence of its reflection in history is the realization of subjective factors and objective conditions for the operation of objective laws. The perfection of social relations in the spiritual sphere of social life is determined by the unity of subjective factors and the objective conditions for the sustainable development of society, and, on the contrary, the stability of the development of society is determined by the perfection of social relations, including in the spiritual sphere of social life, developing on the basis of the available unity of subjective factors and objective conditions .

The conceptual status of social philosophy allows structurally to present national security in the solidity of its numerous substructures and elements.

To counter threats to the national security of Uzbekistan, the forces of its provision (primarily state security and public security) in cooperation with the institutions of civil society ensure the preservation of socio-historical, cultural and spiritual heritage.

On this basis, national priorities for the development of the spiritual sphere are to preserve and strengthen the moral foundations of society, historical traditions, the cultural and scientific potential of the country.

As Islam Karimov said, "people's behavior is not only communication with one another. Morality is, first of all, a conscience, a sense of justice. This - and faith, and honesty "[Karimov 1995: 50].

Preservation of the system of basic values opens up opportunities for the progressive development of the individual, society and the state. In this case, spiritual security presupposes the provision of conditions for stable development and allows the state to solve the urgent tasks of economic, social and political development.

Simultaneously, the analysis of the state of the spiritual, cultural and moral spheres helps to identify those negative trends in various areas of life that can lead to threats to the national security of Uzbekistan. This emphasizes the importance of socio-philosophical analysis, allowing to explore specific forms of self-determination and self-realization of citizens, the patterns and mechanisms of their conscious-volitional and spiritual and moral activities.

Of particular interest is the individual - personal experience in defining the boundaries of selfexpression in accordance with the directions of social development, introducing innovative changes into it, enriching the vital world, forming social mutual support and solidarity, humanistic tendencies in the life of society.

In his work "High spirituality is an invincible force", Islam Karimov calls for the growth of the national consciousness of the Uzbek people, spiritual enrichment, at the same time the renewal and democratization of society, the inculcation of a sense of love for the Motherland, the formation of the worldview of the younger generation in the spirit of modernity. The role of this book by I. A. Karimov is very important, because the scientific, theoretical, historical and modern principles of the concept of "spirituality" are comprehensively explained in it as an unlimited power that elevates a person and strengthens his will and convictions. At the same time, it analyzes the causes and consequences of the dangers threatening our spirituality. This work will undoubtedly serve to further increase the spirituality of our people, will become an important guide to action in the process of spiritual and moral education of youth. 
At present, in the country when building the foundations of a new society, the revival of spirituality, the profound study of the rich historical heritage, the preservation of traditions and customs, the development of culture, art, science and education are inextricably linked with each other, the most important change and growth of the world outlook of society.

An important role in the formation of new social contours of civil society is played by cultural pluralism, which incorporates all elements of spiritual life and ensures equal participation of all individuals in it, create conditions under which the cultural wealth of public consciousness and each individual becomes tangible. Unlimited access to spiritual values helps to overcome the phenomenon of alienation of the individual. Civil society is viable if its members have a high level of social, intellectual, psychological development, internal freedom and are capable of independent action when including in this or that institution of public life.

In the international politics of today, unique processes are taking place. In interstate relations, the method of "influencing another" has moved into the most complex sphere - the sphere of spirituality. Now states are eliminated by other states not with the help of weapons, force, property wealth, but through spiritual and ideological movements. The ideas, as well as the spirituality of the ruling state (more precisely, the hegemon) at the world level will always remain the dominant ideas and spirituality.

It is the states striving for hegemonism that limit the spirituality of other peoples. Only with the unconditional assimilation by some people of vocabulary, political ideas, "spirituality" of the ruler, we can say that this people is obedient.

Today, spirituality is transformed into the most effective and uncompromising weapon. Today, the strongest countries of the world are subjecting their political, strategic, geopolitical, economic positions, arsenal of weapons, to the service of spiritual violence.

Every human society, every civilization is built on the basis that has been formed, throughout history and has shown its potential of spiritual heritage.

In every civilization, the lifestyle, mentality, culture, social, economic and political structure, regardless of the philosophy and form of religion, are manifested in this high spiritual heritage. If this spiritual heritage is damaged, society, civilization, states are doomed to disappearance or sharp transformation. Historical experience shows that as soon as spiritual and cultural pillars restrain the state, it is possible to make a conclusion about the beginning of his death.

For what reasons does the spirituality of the Republic of Uzbekistan become a target? According to Sh. Pakhrutdinov, our high ideology is embodied around the trend "now, when the clash of different political interests occurs on the international arena, only the people and society having their own opinion, their vital position turn into an invincible force and is able to build their future with their own hands and mind ". Under such conditions it is advisable to reflect, in particular, on the threats of destructive ideological movements to the sovereignty of independent states.

The fact is that to date, no aggressive state has a need to deprive another state of independence, turn it into its colony and declare it its dominion or protectorate. The logic of the political and economic globalization taking place in the world calls for states to preserve their independence. At the same time, globalization requires states to give up sovereignty to a certain extent. This aspect of globalization has a number of positive sides and, at the same time, it is a bypassing or tacit truth. In any case, for some states, instead of claiming "only my state exists in the world", a feeling like the concept of "planetary power" would be attractive.

Turning to the origins of the word "sovereignty", it comes from the Latin word supremitas or suprema potestas - "supreme authority", then from the French word "sovereignty" and means dominance over the supreme power at the state level. Sovereignty is the primary condition and sign of the state. The logical and evolutionary basis was the announcement of its sovereignty a year before its acquisition in 1991 by our country of independence. However difficult the achievement of sovereignty, Uzbekistan has fully achieved it and successfully strengthened it for 26 years [Pakhrutdinov 2006: 45- 47].

Despite this, the leaders should be interested in the mechanisms of different destructive spiritual and ideological movements, the strategy of confronting them. 
Any threats aimed at spirituality, in themselves, turn into one of the serious dangers, which in the results will lead to a crisis of society.

Using a factor of spirituality, you can create various dangers. Because she has certain qualities that ensure stability in society. And they rely on the following factors:

- It is associated with the mind, thinking and soul of man, which is considered the main artery of spirituality. With the conquest of reason and the thinking of man by destructive ideas that are contrary to development, a person becomes a victim and a novice of these ideas;

- The ongoing changes in the national mind, mentality and soul of a person are reflected in his spirituality - the national consciousness, traditions, values of the people.

Therefore, changes or seizure of the mind, mind, soul and national thinking of man is considered the main factor. You can subordinate a person without using weapons [Otamuratov 2015: 192-196]. One of the factors ensuring the stability of society is national ideology. With the achievement of state independence by our Motherland, the need to change people's minds in accordance with the goals of building a legal democratic state, a free civil society, increasing the spirituality of the people became evident. The issues of forming the idea of national independence, reflecting the patterns of independent development and meeting the basic interests of the people of Uzbekistan, became topical. The course of 25 years has accumulated experience, which showed that a person, a society can not exist without an idea and ideology. For consciousness, the soul of a person lives, constantly feeling the need for a life idea, which motivates him to active activity, capable of finding answers to numerous questions.

Just as there is no vacuum in nature, in society, there can be no spiritual emptiness in the mind and heart of man. If healthy ideas do not prevail in society, the heart and minds of people will win alien, harmful ideas that destroy the way of life of the people.

Today it became obvious that just as different state forces are struggling to share the riches of the world, so too are all sorts of aggressive currents and teachings that compete among themselves to win hearts and people's consciousness, wanting to turn them into weapons of achievement of their selfinterested, interesting goals.

Proceeding from this, the achievement of our noble goals, the final liberation from the old ideological dogmas, the avoidance of ideological vacuum, protection from encroachments of alien ideas, the education of comprehensively developed personalities - all this requires the formation of a new ideology that corresponds to the interests of our society.

No nation, clearly representing its life goals, caring about its future, has never lived and can not live without a national idea and ideology. Without an idea, any state and society, not to mention a person, will inevitably go astray.

The national idea is designed to express the dreams and aspirations of the people, to support it, to support its spirit in historical trials, when the society is looking for the solution of a multitude of emerging vital problems. It is needed not only for the creation of material wealth and abundance, but is also an incentive for striving to achieve high morality, a torch that illuminates the path to progress.

The national ideology is based on the noble age-old aspirations of the multinational people of Uzbekistan, its ideals on the way to creating a free and prosperous homeland, a dignified and prosperous life.

The main goal of the national ideology is to unite the people in the name of a great future, to induce every citizen of the country, regardless of his nationality, linguistic and religious affiliation, to live with a sense of permanent responsibility for the fate of his homeland; To bring up pride for the richest heritage of ancestors, the accumulated spiritual values and noble traditions; Form highly moral and harmoniously developed people; Make the meaning of life a dedication for the sake of our sacred land.

The national idea should serve the people, help everyone, realize themselves in the realities of a rapidly changing world, feel the successor to the heritage of great ancestors, created by them an original millennial culture, try to protect and multiply this wealth, supplemented in the context of universal values, growing generation. 
It is very important in the current conditions of overcoming the ideological vacuum to create ideological immunity among our people, first of all among the younger generation. We think there is no need to explain in detail the increased role of ideology in modern conditions, when, in the context of an information explosion, the process of globalization, the desire of certain forces to expand their sphere of influence is manifested, thereby dividing the world space into confrontation fields. For all of us, the need to take into account the ideological situation in the post-Soviet space, the situation in the Central Asian region, the importance of filling the vacuum that emerged as a result of abandoning the old ideology, new - the ideology of national independence, must be clear to actively oppose attempts to penetrate alien ideology and destructive ideas in Uzbekistan.

Thus, with the efforts of the general public, intellectuals, scientists and cultural workers, primarily workers in the spiritual and educational sphere, to raise to a new level the activities aimed at improving and affirming the basic principles of national ideology in the minds of people. Especially it should be noted that for us the most important goal is the transformation of the national idea and the ideology of independence into the basis of the world view, the spiritual core of every person living in our country.

\section{REFERENCES}

[1] Karimov I. A. As a security and peace. T. 6. Tashkent: Uzbekistan, 1998. (in Russian)

[2] Karimov, I.A. Uzbekistan national independent, economy, politics, ideology. T. 1. Tashkent: Uzbekistan, 1996. (in Russian)

[3] Karimov, I. A. The high value laws, freedom of human. T. 14. Tashkent: Uzbekistan, 2006. (in Russian)

[4] Karimov I.A/ High Spirituality - Strength of Power. T: "Spirituality", 2008. (in Uzbek)

[5] Kara-Murza S.G. Demonstration in naroda. M .: Algorithm, 2008. (in Uzbek)

[6] Otamuratov O Globalization and national-spiritual security.T: Uzbekistan, 2015. (in Uzbek)

[7] Erkaev A. Spirituality and development. T .: "Manaviat", 2007. (in Russian)

[8] Muskhalishvili NL, Sergeev VM, Shreider Yu. A. Value reflection and conflicts in a divided society //9.Issues of Philosophy. 1996. № 11. . (in Russian)

[9] Pakhrutdinov, Sh. I. Threat to development: theory and practice. Tashkent: Academy, 2006. (in Uzbek)

\section{AUTHOR's BIOGRAPHY}

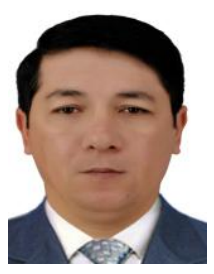

Avazov Komil Hollyevich. Graduate student 2007-2010 of the Moscow State Pedagogical University. Since 2014, Senior Lecturer of the Department of Humanitarian and Economic Sciences of the Surkhandarya Regional Institute for Advanced Studies and Retraining of People's Education Workers of the Republic of Uzbekistan. Since 2015, the docent has been a student of the Uzbek National University named after Mirzo Ulugbek (Uzbekistan) (Tashkent.)

Citation: Avazov, Komil Hollievich. "Spiritual and Moral Aspects of the Formation of a sustainable Society." International Journal of Humanities Social Sciences and Education (IJHSSE), vol 4, no. 10, 2017, pp. 1-9. doi:http://dx.doi.org/10.20431/2349-0381.0410001.

Copyright: (C) 2017 Authors. This is an open-access article distributed under the terms of the Creative Commons Attribution License, which permits unrestricted use, distribution, and reproduction in any medium, provided the original author and source are credited. 